\section{Evolución del tétanos y niveles de pseudocolinesterasa}

\section{Sr. Director:}

El tétanos es una patología de interés de un lado por su alta mortalidad, baja frecuencia $(0,15$ por millón de habitantes en Estados Unidos durante el final de la década de los ochenta y principio de los noventa) (1), y alto grado de recursos que conlleva su tratamiento en las unidades de cuidados intensivos, siendo una parte importante de éste el empleo de sedación. Comentamos aquí el caso de una paciente afectada por un tétanos que ingresó en nuestra unidad, postulando la posibilidad de la monitorización de la evolución de la enfermedad, y por tanto de los requerimientos de sedación, a expensas de los niveles de pseudocolinesterasa, hecho ya recogido en la literatura aunque de escasa difusión.

Paciente de 71 años de edad, intervenida de nódulo tiroideo, que ingresa en nuestro hospital por cuadro de contractura muscular localizada a nivel de los músculos faciales y cervicales. Había sufrido nueve dias antes una herida incisa en cuero cabelludo (suturada en su centro de salud), sin recibir vacunación antitetánica. En su evolución inmediata, la paciente desarrolló cuadro de opistótonos y aparición de "risa sardónica", planteándose entonces el diagnóstico de tétanos e ingresando en nuestra unidad. Ante la dificultad respiratoria que presentaba se procede a intubación orotraqueal y conexión a ventilación mecánica, con posterior realización de traqueotomía. Se practicaron cultivos de la herida en cuero cabelludo en los que no se obtuvo crecimiento. La paciente fue sedada con diacepam y pancuronio intravenosos (a dosis de 60-70 mg de diacepam y $24 \mathrm{mg}$ de pancuronio cada 24 horas), analgesiada con $80 \mathrm{mg} /$ día de morfina, iniciandose tratamiento empírico antibiótico con penicilina ( 2 millones de ui i.v./ 4 h), presentando en esos momentos unos niveles bajos de pseudocolinesterasa plasmática (la cifra era de 5.430, siendo el rango de 7.000-19.000 ui/l). En su evolución hubo de incrementarse la dosis de diacepam hasta alcanzar $450 \mathrm{mg} / 24 \mathrm{~h}$ ante el incremento del cuadro de contractura muscular, requiriendo esta dosis máxima entre los dias 10 a 15 de su ingreso, dias que coincidieron con los niveles más bajos en la colinesterasa sérica (y siempre por debajo de la normalidad, en torno a los 5.000 ui/l). Coincidiendo con el cese progresivo de la hipertonía, los niveles de pseudocolinesterasa fueron ascendiendo hasta normalizarse, pudiendo retirarse el empleo de la sedación. La paciente fue dada de alta a los 50 dias de su ingreso, encontrándose en su domicilio valiéndose por sí misma.

El tétanos es un cuadro de escasa frecuencia, y aún lo es más desde la universalización de los programas de vacunación (2). Su morbimortalidad se ha modificado con la existencia de las Unidades de Medicina Intensiva (3), lugares donde va a poderse llevar a cabo el tratamiento requerido para esta enfermedad. El tiempo de estancia va a venir definido generalmente por el tiempo requerido de sedación, piedra angular del tratamiento (junto con los relajantes) para control de la hipertonía y espasmos musculares. Durante el tiempo de inmovilidad ocurre un catabolismo importante secundario a la sobreactividad del sistema nervioso simpático, lo que conlleva una importante pérdida de masa muscular, lo que puede dar origen a complicaciones en la recuperación posterior del paciente, siendo importante que el tiempo que el paciente requiera sedación sea el menor posible para que la repercusión sea mínima, y de ello la importancia de monitorizar el empleo de sedorrelajación.

Se sabe que la base patológica es sobreactividad de la motoneurona a causa de la excesiva síntesis de acetilcolina (4), encontrándose su almacenamiento y liberación incrementados, y añadiendose a ello la actividad colinérgica ya descrita que tiene la toxina "per se" (4), actuando la sedación sobre esta sobreactividad. Es un hecho poco difundido que los niveles de la pseudocolinesterasa están disminuidos en la infección por el tétanos, niveles que experimentan cambios de acuerdo a la evolución de la enfermedad: se ha objetivado que la disminución se correlaciona con el grado de severidad, observándose un descenso al inicio de la enfermedad para incrementarse con posterioridad (en concordancia con la mejoría de los pacientes) (5), probablemente niveles bajos de la enzimas presupongan un curso severo y prolongado u ominoso. Desde 1938, ha habido autores que han considerado este punto, llegándose a postular el empleo de oximas en esta patología al igual que ocurre en la intoxicación por organofosforados $(6$,$) , aunque ellos mismos han tenido que noti-$ ficar la falta de resultados apreciables.

En nuestro caso, los niveles de pseudocolintesterasa fueron inferiores a la normalidad en las etapas iniciales de la enfermedad, etapas en las que la paciente requirió mayor empleo de sedación a expensas de diacepam e incluso relajación muscular, destacando como el incremento de esta enzima se acompañó de una mejoría clínica y por ello menor dosis de sedación. La explicación de porqué los niveles de la enzima no siguieron descendiendo pudiera estar en la efectividad del tratamiento recibido. 